www.jmscr.igmpublication.org

Impact Factor 5.84

Index Copernicus Value: 83.27

ISSN (e)-2347-176x ISSN (p) 2455-0450

crossref DOI: _https://dx.doi.org/10.18535/jmscr/v5i2.139

Journal Of Medical Science And Clinical Research

IGM Publication

An official Publication of IGM Publication

\title{
Results of Ipsilateral Hip and Shaft Femur Fractures Treated with two Separate Implants- A Prospective Study of 20 Cases
}

\author{
Authors \\ Dr B.Sravanthi ${ }^{1}$, Dr R.Srikanth Varma ${ }^{2}$, Dr Khader Basha ${ }^{3}$, Dr Ram Prasad $\mathbf{R}^{4}$ \\ ${ }^{1,2}$ M.S Orthopedics Kamineni Hospital Hyderabad \\ ${ }^{3}$ DNB Orthopedics Kamineni Hospital Hyderabad \\ ${ }^{4}$ M.S Orthopedics \& DNB Kamineni Hospital Hyderabad
}

Email-drsravs73@gmail.com

\begin{abstract}
Background: Treatment of ipsilateral fractures of hip and shaft femur is difficult and associated with high rate of complications. Choosing the right implant for this challenging problem is very essential to expedite optimum result with minimal complications.

Method: 20 patients with ipsilateral fractures of hip and shaft femur were treated with two individual implants at each fracture site and followed up for 2 years .The functional outcome, complications were critically evaluated.

Results: 18 femoral neck fractures united uneventfully. There was one case of non union and one case of osteonecrosis. Among 20 femoral shaft fractures, two went in to non-union, requiring secondary surgical procedure. There was one case of infection at the shaft fracture site, which healed with debridement and antibiotics.

Conclusion: management of ipsilateral fractures of hip and shaft of femur with two separate implants not only gives best results but managing complications is better with this protocol.
\end{abstract}

\section{INTRODUCTION}

Management of multiple fractures is a challenging problem and it is even more challenging to manage more than one fracture in the same bone. One such complex scenario is the management of ipsilateral fractures of proximal femur and shaft. Challenges start right from identifying the ipsilateral fracture neck femur from more obvious shaft fracture, decision making about timing of surgery and choosing the right implant. The incidence $^{1}$ of this fracture combination is about $2.5 \%$ to $6 \%$ and most are due to high energy trauma ${ }^{4}$. Reported incidence of missing a fracture is as high as $20-30 \%$. Advances in imaging, operative techniques and plethora of implant designs have created dilemma in choosing the better implant for optimum result. The purpose of this study is to critically analyse the functional outcome following the treatment of ipsilateral proximal and shaft femur fractures with special emphasis on managing the complications which are inherent in this type of fractures.

\section{MATERIAL AND METHODS}

We report a prospective study of consecutive 20 patients with ipsilateral fractures of proximal and shaft femur, treated with two separate implants for each fracture between 2014-2015. Patients were followed up for an average period of 2 years.

Study includes 20 patients of which 18 were male and 2 females with an average age of 34 years [18-55]. The mode of injury in majority of 
patients was RTA in 16 [80\%] and it was fall from height in $4[20 \%]$. Ten patients have significant associated injuries, 4 patients have blunt injury to abdomen, 2 had hemothorax and two patients had head injury. Two of the patients had fractures in other regions, one had humerus fracture with an elbow dislocation and one had a pelvic injury with pubic rami fracture.

Femoral neck fractures were classified according to Garden's classification and inter- trochanteric fractures with Boyd and griffin's criteria. Out of 20 patients, 12 patients had femoral neck fractures of which, 4 patients with grade 1, 3 with grade2, 2 with grade 3 and 3 with grade 4 severities. Trochanteric fractures were 8 which include 3 type 1, 2 type 2 and one type 3 and two were type 4. Femur shaft fractures were classified according to Winquist and Hansen system, there were 6 type 1, 10 type2, 2 type 3 and 2 type 4 .

Table.1demographics

\begin{tabular}{|l|l|l|}
\hline & Males & Females \\
\hline Number of Patients & 18 & 2 \\
\hline
\end{tabular}

Age Distribution

Table .2 fracture types

\begin{tabular}{|c|c|}
\hline Age & No.Of Patients \\
\hline $15-25$ years & 6 \\
\hline $25-35$ & 8 \\
\hline $35-50$ & 4 \\
\hline$>50$ & 2 \\
\hline
\end{tabular}

Table-3 -Fracture distibution

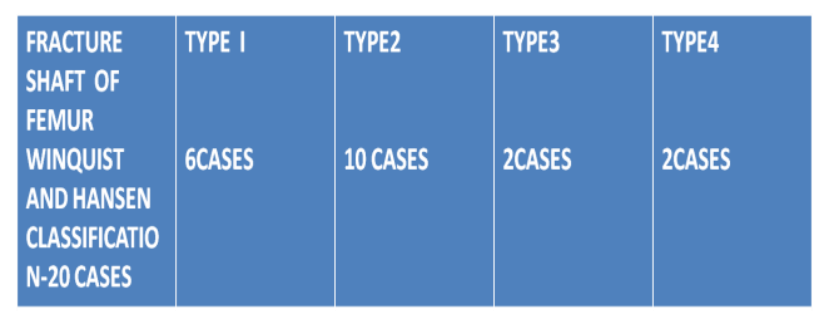

Table-4 Fracture distibution

\begin{tabular}{|c|c|c|c|c|}
\hline $\begin{array}{l}\text { NECK } \\
\text { FRACTURES. } \\
\text { GARDENS } \\
\text { CLASSIFICATIO } \\
\text { N-12CASES }\end{array}$ & $\begin{array}{l}\text { TYPEI } \\
7 \text { CASES }\end{array}$ & \begin{tabular}{|l} 
TYPE 2 \\
5 CASES
\end{tabular} & $\begin{array}{l}\text { TYPE3 } \\
\text { NIL }\end{array}$ & $\begin{array}{l}\text { TYPE4 } \\
\text { NIL }\end{array}$ \\
\hline $\begin{array}{l}\text { BOYDAND } \\
\text { GRIFFTH- } \\
\text { 8CASES }\end{array}$ & $\begin{array}{l}\text { TYPE1 } \\
3 \text { CASES }\end{array}$ & $\begin{array}{l}\text { TYPE2 } \\
\text { 2CASES }\end{array}$ & $\begin{array}{l}\text { TYPE3 } \\
\text { 1CASE }\end{array}$ & $\begin{array}{l}\text { TYPE } 4 \\
2 \text { CASES }\end{array}$ \\
\hline
\end{tabular}

Table-5-Implants Used -And Number Of Patients

\begin{tabular}{|c|c|c|c|}
\hline & CC SCREWS & DHS & PFLC \\
\hline DCP & 4 & 1 & 0 \\
\hline DFN & 8 & 6 & 1 \\
\hline
\end{tabular}

DCP-Dynamic Compression ,DFN-Distal Femoral Nail, CC SCREWS- CannulatedCancellousScrews,DHS-Dynamic Hip Screw, PFLCP-Proximal Femoral Locking Plate

\section{TREATMENT PROTOCOL}

Patients were initially assessed in emergency department managed according to ATLS guidelines.

After adequate resuscitation and hemodynamic stabilization is achieved, fractures and dislocateions were carefully evaluated, reduced and proper splintage and traction was applied. Patients with associated injuries like head injury, chest and abdominal injuries were evaluated by concerned teams and definitive stabilization of fractures were done within $24-48 \mathrm{hrs}$.

As a protocol, shaft fracture was stabilized first followed by femur neck fixation on a fracture table.

15 patients were treated with retrograde nailing and 5 cases managed with lcp to stabilize femur shaft fracture.

Inter trochanteric fractures were stabilised with DHS and femoral neck fractures with cancellous screws. One basicerviacal fracture with sagittal split in trochanter was stabilized with proximal femoral plating.

Average blood loss was $200 \mathrm{ml}$ and average operating time was $4 \mathrm{hrs}$.

Drain removal was done on $2^{\text {nd }}$ post operative day and mobilization exercises were started.

Average duration of hospital stay was 7 days.

Patients were followed up weekly for first two weeks followed by once every 4 weeks. Suture removal done at the end of two weeks. Check $x-$ rays done at 4week intervals to monitor the fracture healing.

Partial weight bearing started once the callus is seen at the fracture site.

Results were analysed with radiographic assessment of fracture union and Friedman and wyman functional outcome assessment. 


\section{JMSCR Vol||05||Issue||02||Page 18104-18108||February}

\section{RESULTS}

Patients were followed up for 16 to 32 (mean, 24) months .Out of 20 femoral neck fractures, $18(90 \%)$ achieved union in a mean of 4 (range, 25) months, of which $17(85 \%)$ healed anatomically. There was $1(5 \%)$ case of non-union, and one ended up in osteonecrosis of the femoral head noted at $6^{\text {th }}$ month. In fracture shaft, 18 cases united (mean time -5months) and 2 cases went in to non-union and were treated with secondary bone grafting.

2 patients developed infections (1superficial and 1 deep) and resolved following debridement and antibiotic treatment.

No patient had hip infection or fat embolism.

$17(85 \%)$ patients had a good functional result, in $2(10 \%)$ the result was fair, and in $1(5 \%)$ it was poor.

Table-6 - Complications

\begin{tabular}{|c|c|}
\hline Neck of femur complications & No.of patients \\
\hline nonunion & $5 \%$ \\
\hline osteonecrosis & $5 \%$ \\
\hline infection & 0 \\
\hline Varusmalunion & 0 \\
\hline
\end{tabular}

Table-7-Complications

\begin{tabular}{|c|c|}
\hline Shaft of femur complications & No.of patients \\
\hline Non union & $10 \%$ \\
\hline Superficial infection & $5 \%$ \\
\hline Delayed union & $5 \%$ \\
\hline
\end{tabular}

Table-8 Functional Outcome Criteria-Friedman and Wymann Criteria

\begin{tabular}{|c|c|c|c|}
\hline Result & $\begin{array}{c}\text { Impaired } \\
\text { Activity of } \\
\text { Daily Living }\end{array}$ & Pain & $\begin{array}{c}\text { Loss Of Hip } \\
\text { Or Knee } \\
\text { Range Of } \\
\text { Motion }\end{array}$ \\
\hline GOOD-17 & NO & NIL & $<20 \%$ \\
\hline FAIR -2 & MILD & $\begin{array}{c}\text { MILD TO } \\
\text { MODERATE }\end{array}$ & $20-50 \%$ \\
\hline POOR-1 & MODERATE & SEVERE & $>50 \%$ \\
\hline
\end{tabular}

Table 9-Results

\begin{tabular}{|l|c|}
\hline Results & No.of patients \\
\hline Good & $17(85 \%)$ \\
\hline Fair & $2(15 \%)$ \\
\hline poor & $1(5 \%)$ \\
\hline
\end{tabular}

\section{DISCUSSION}

The association of fracture shaft of femur with ipsilateral proximal femur fracture is unique and needs special consideration because of following reasons:

1. Incidence of missed fractures during initial presentation is significantly high, reported incidence is $19-31 \%^{5,6}$

\section{Figure-1}

Figure-2

Figure-3

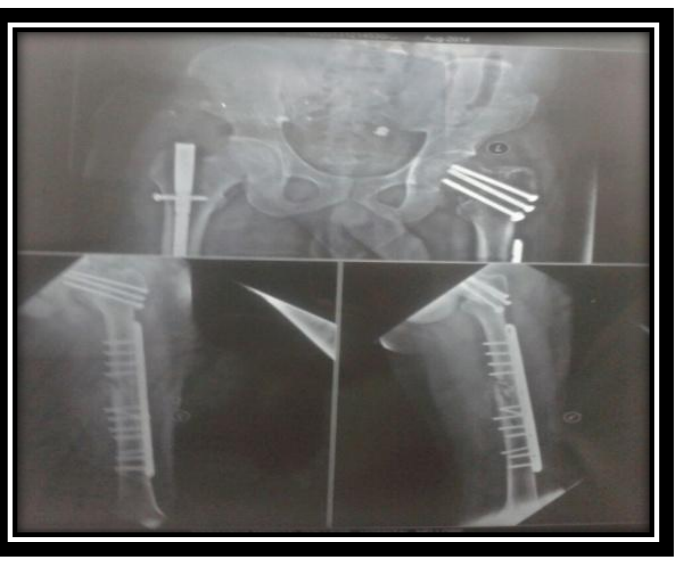


2. Though varieties of treatment protocols exist, there is still no consensus ${ }^{2,3}$ about choice of implant.

3. There are no clear guidelines as to which fracture has to be fixed first, and the timing of surgery.

4. Complication rates are high in managing these fractures and there is steep learning curve.

Missing the proximal femur fracture at the initial presentation is one of the reasons of compromised results following surgical treatments of these complex injuries. Fracture neck of femur needs early and accurate reduction for good functional outcome. Reported incidence of missing these important neck fractures associated with more obvious shaft fractures of femur is as high as $30 \%$. High index of suspicion is needed whenever a trauma with involvement of exchange of high energy is encountered. In our study, there are no missed injuries, as we examine the radiographs of pelvis with both hip joints in all the patients with high velocity injury, as a protocol.

There are varieties of treatment protocols for the management of ipsilateral hip and shaft fractures of femur. In the process of evolution of these methods, starting from conservative line of management to surgical stabilization with newer models of implants, world has seen variety of implants and treatment protocols. But none has proved their complete superiority over other.

"Miss a nail technique",7: cancellous screw fixation of femoral neck fracture around the nail is an option but there are high chances of malunion ${ }^{8}$ and non union. In this technique, achieving a good reduction is also very difficult.

The newer methods of fixation ${ }^{9}$ include simultaneous fixation of proximal and shaft fracture with a single implant like reconstruction nail, Gamma nail and long PFN. They have the advantage of minimal soft tissue dissection, lesser blood loss and if closed reduction is achieved an added advantage of maintaining the fracture biology. Their mechanical strength is superior to screw fixation of femoral neck fractures ${ }^{14}$. The disadvantages of using nails with pyriform fossa entry, there are high chances of avascular necrosis as reported by Swiontowskiet $\mathrm{al}^{1}$. The gamma nails are another widely used fixation system, has disadvantages of high incidence of superior migration of nail and there by leading to varus collapse. Long PFN has overcome the draw backs of the earlier two nail systems with its design which has 6 degree proximal mediolateral angle and its trochanteric entry has advantages of easy insertion unlike other nails which have pyriform entry there by theoretical advantage of preserving vascularity and avoiding the need to keep the thigh excessively adducted for nail insertion which may result in varus mal reduction ${ }^{14}$.

Oh et. al., suggested retrograde nailing for the femoral shaft fractures and cancellous screw fixation for femoral neck fractures ${ }^{13}$.

We report our results of treating ipsilateral fractures of proximal femur and shaft of femur with two separate implants for each fracture instead of one implant addressing the two fractures. The results in our study are comparable to studies where single implant was used ${ }^{10,11,12} \mathrm{We}$ have achieved $95 \%$ of primary union of femoral neck fractures and 90\% union at femoral shaft fracture. The complications are 1 case of femoral neck non union and 1 case of osteonecrosis of femoral head. Functional outcome as assessed with Friedman and Wyman classification shows good results in $85 \%$ of cases. Femoral shaft was stabilized first in all the cases. All the patients were taken up for surgery within $24 \mathrm{hr}-48 \mathrm{hrs}$ of trauma.

The major complications encountered in treating these injuries are

1. Non union

2. Osteonecrosis of femoral head

3. Mal union

We propose the option of using two separate implants in place of single implant in these injuries as managing the complications is easier and better. The advantage with two separate implants is, when one fracture site is complicated with infection, non union or malunion and other fracture healing is in good progress, one can address the fracture site with complication without disturbing the other. Osteonecrosis of the femoral 
head needs replacement with prosthesis and this can be easily done when two separate implants are used. Once the femoral shaft fracture is reduced and stabilised, it is easy to reduce the femoral neck fracture anatomically and stabilise with cancellous screws. It is difficult to achieve the reduction at both the fracture sites ${ }^{13}$ and one may have to compromise on the reduction when single implant is used. Reported incidence of intraoperative difficulty in achieving reduction can be as high as $52 \%$ and distraction at the fracture site is $28 \%$ which are significant .The single implant fixation of two fractures is technically demanding and has steep learning curve.

\section{CONCLUSION}

Ipsilateral hip and shaft femur fractures are difficult to treat and are associated with high rate of complications. Managing the fractures with two separate implants has similar good results as when single implant was used. It has advantages of easier and better ways to treat the complications.

\section{REFERENCES}

1. Swiontowski M, Hansen S, Kellam J. Ipsilateral fractures of the femoral neck and shaft- a treatment protocol. J Bone Joint Surg Am 1984;66:260-8.

2. Wu CC, Shih CH. Ipsilateral femoral neck and shaft fractures. Retrospective study of 33 cases. Acta OrthopScand 1991;62: 346-51

3. Russell TA. Ipsilateral femoral neck and shaft fractures. ClinOrthopRelat Res 1986;208:188-94.

4. Friedman RJ, Wyman ET Jr. Ipsilateral hip and femoral shaft fractures. ClinOrthopRel Res 1986;208:1880-94.

5. Alho A. Concomitant Ipsilateral fractures of the hip and femoral shaft of Femur. A systematic review of 722 cases. Ann Chir Gynaecol 1997;86:326-36.

6. Bucholz RN, Rathjen K. Concomitant Ipsilateral fractures of the hip and femur treated with interlocking nails. Orthopaedics 1985;8:1402-6

7. Chaturvedi S, Sahu SC. Ipsilateral concomitant fractures of the femoral neck and shaft. Injury 1993;24:243-6.

8. Wiss DA, SimaW, BrienWW, Ipsilateral fractures of femoral neck and shaft.J.Ortho Trauma 1992;6;159-66

9. Dousa P, Bartonicek J, Jehlicka D, Skala-Rosenbaum J. Osteosynthesis of trochanteric fracture using proximal femoral nail. ActaChirOrthopTraumatol 2002;69:22-30.

10. Gamma nail in treatment of ipsilateral fracture of shaft and neck of the femur

11. SushrutBabhulkar, SudhirBabhulkar et al. Indian J Orthop, 2005 oct;volume 39:number 2:p.104-107

12. Analysis of the results of ipsilateral hip and shaft femur fractures treated with reconstruction nailRajnishGarg, JL Bassi, M Yamin. Indian J Orthop 2006 april;volume 40:p.238-24214

13. Long proximal femoral nail in ipsilateral fractures proximal femur and shaft of femur WM Gadegone, Vijayanand Lokhande, Yogesh Salphale, Alankar Ramteke. Indian J Orthop, 2013 may; volume 47.issue 3

14. Retrograde nailing with subsequent screw fixation for ipsilateral femoral shaft and neck fractures

15. Oh CW,OhJK, Park BC, Jeon IH et al Arch Orthop Trauma Surg.2006 sept;126 (7);448-53

16. Ramser JR, Mihalko WM, Carr JB, Beaudoin AJ, Kruse WR. A comparison of femoral neck fixation with the reconstruction nail versus cancellous screws in anatomic specimens. ClinOrthopRelat Res 1993;290:189-96

17. Bose WJ,Coarces A,Anderson LD.A prelimnary experience with Russel TAYLOR reconstruction nail for complex femoral fractures .J. Trauma 1992:32:71-6. 